\title{
Structure-dependent immunostimulatory effect of CpG oligodeoxynucleotides and their delivery
} system

\section{Nobutaka Hanagata}

Nanotechnology Innovation Station, National Institute for Materials Science, Tsukuba, Ibaraki, and Graduate School of Life Science, Hokkaido University, Kita-ku, Sapporo, Japan
Correspondence: Nobutaka Hanagata Nanotechnology Innovation Station, National Institute for Materials Science, I-2-I Sengen, Tsukuba, Ibaraki 305-0047, Japan

Tel +8I 298604774

Fax +8I 298592475

Email hanagata.nobutaka@nims.go.jp
This article was published in the following Dove Press journal:

International Journal of Nanomedicine

24 April 2012

Number of times this article has been viewed

\begin{abstract}
Unmethylated cytosine-phosphate-guanosine (CpG) oligodeoxynucleotides (ODNs) are recognized by Toll-like receptor 9 (TLR9) found in antigen-presenting cells and B cells and can activate the immune system. Using CpG ODNs as an adjuvant has been found to be effective for treating infectious diseases, cancers, and allergies. Because natural ODNs with only a phosphodiester backbone are easily degraded by nuclease (deoxyribonuclease [DNase]) in serum, CpG ODNs with a phosphorothioate backbone have been studied for clinical application. CpG ODNs with a phosphorothioate backbone have raised concern regarding undesirable side effects; however, several CpG ODNs with only a phosphodiester backbone have been reported to be stable in serum and to show an immunostimulatory effect. In recent years, research has been conducted on delivery systems for CpG ODNs using nanoparticles (NPs). The advantages of NP-based delivery of CpG ODN include (1) it can protect CpG ODN from DNase, (2) it can retain $\mathrm{CpG}$ ODN inside the body for a long period of time, (3) it can improve the cellular uptake efficiency of $\mathrm{CpG}$ ODN, and (4) it can deliver CpG ODN to the target tissues. Because the target cells of CpG ODN are cells of the immune system and TLR9, the receptor of CpG ODN is localized in endolysosomes, $\mathrm{CpG}$ ODN delivery systems are required to have qualities different from other nucleic acid drugs such as antisense DNA and small interfering RNA. Studies until now have reported various NPs as carriers for $\mathrm{CpG}$ ODN delivery. This review presents DNase-resistant $\mathrm{CpG}$ ODNs with various structures and their immunostimulatory effects and also focuses on delivery systems of CpG ODNs that utilize NPs. Because CpG ODNs interact with TLR9 and activate both the innate and the adaptive immune system, the application of CpG ODNs for the treatment of cancers, infectious diseases, and allergies holds great promise.

Keywords: Toll-like receptor 9 (TLR9), immunostimulation, higher-order nanostructure of DNA, delivery system, nanoparticles
\end{abstract}

\section{Introduction}

Unmethylated cytosine-phosphate-guanosine $(\mathrm{CpG})$ dinucleotide is recognized by Toll-like receptor 9 (TLR9) and induces immune response. Immune activity in DNA was first discovered when a DNA fraction of Bacille Calmette-Guérin was found to produce type I interferon (IFN), leading to the activation of natural killer cells; the antitumor effect of this induction was recognized. ${ }^{1}$ Krieg et $\mathrm{al}^{2}$ elucidated that immune response is caused only when $\mathrm{CpG}$ is included in the DNA, and that immune response is inactivated when the cytosine residue is methylated. This $\mathrm{CpG}$ sequence is found with high frequency in bacterial DNA, and only occasionally in mammalian DNA. Because CpG in mammalian DNA is methylated, it is believed that the recognition of unmethylated $\mathrm{CpG}$ sequence is an action by the immune system to recognize the DNA 
of bacteria and eliminate it. It was then discovered that TLR9 is the receptor of DNA containing unmethylated $\mathrm{CpG}^{3}$

In human beings, TLR9 is mainly expressed by B cells and plasmacytoid dendritic cells (pDCs). ${ }^{4} \mathrm{CpG}$ stimulates these cells and induces innate and adaptive immune responses (Figure 1). B cells whose TLR9 is activated by CpG secrete cytokines important to the innate immune system - including IL-6, IL-10, and IL-12 - using nuclear factor-kappa B and other signal transduction pathways. ${ }^{2,5,6}$ IL-6 and IL-12 secreted from $\mathrm{B}$ cells are also involved in adaptive immune response. IL-6 promotes the multiplication and activation of B cells; as a result, the production of antibodies is enhanced. ${ }^{7,8}$

pDCs whose TLR9 is activated by CpG secrete cytokines involved in innate immune response, including type I IFNs and tumor necrosis factor-alpha (TNF $\alpha) .{ }^{9}$ These pDCs also activate natural killer cells. ${ }^{10}$ Furthermore, pDCs with activated TLR9 secrete IL-12 and promote the differentiation of T helper (Th) 0 into Th1, ${ }^{11-13}$ as well as inducing Th1 to migrate to B cells through the actions of IFN- $\gamma$-inducible protein of $10 \mathrm{kDa}$ (IP10). ${ }^{14,15} \mathrm{~B}$ cells that interact with Th1 differentiate into plasma cells, which possess the ability to produce antibodies, playing a central role in adaptive immunity. Also, IFN- $\alpha$ promotes CD8-positive cytotoxic T lymphocyte response. ${ }^{16,17}$
Because immune response mediated by the activation of TLR9 induces not only the innate immune system but also the adaptive immune system, its application for treating illnesses including infectious diseases, cancers, allergies, and asthma holds great promise. ${ }^{18-21}$ Until now, various CpG oligodeoxynucleotides (ODNs) have been developed to induce immune response via the activation of TLR9. What is most important in the clinical application of CpG ODN is protecting $\mathrm{CpG}$ ODN from DNase and delivering $\mathrm{CpG}$ ODN to the TLR9 of pDCs. Chemical modification of $\mathrm{CpG}$ ODN is an effective technique to protect against degradation by DNase. However, several severe side effects caused by the modification of DNA backbone have been reported. For example, repeated administration of backbone-modified $\mathrm{CpG}$ ODNs has resulted in reduced immune responses, lymphoid follicle destruction, and organ enlargement. ${ }^{22}$ DNase-resistant natural $\mathrm{CpG}$ ODNs consisting entirely of phosphodiester backbone are, therefore, desirable for clinical application, but so far most clinical trials have been conducted using backbone-modified CpG ODNs. Encapsulating CpG ODN and sealing it inside nanoparticles (NPs) is also an effective method to protect ODN against break down by DNase. NPs may make it possible to use naturally occurring $\mathrm{CpG}$ ODNs in clinical applications.

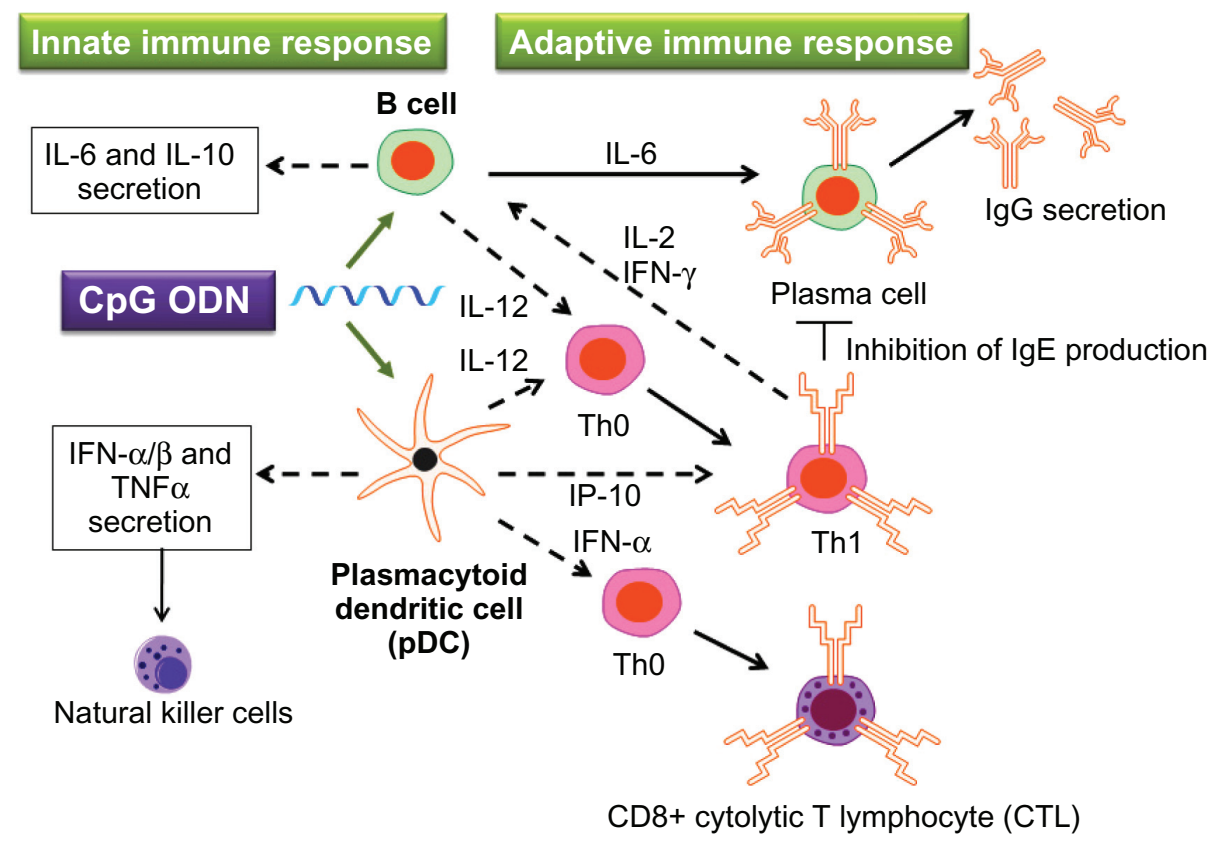

Figure I Immunostimulatory effect of cytosine-phosphate-guanosine (CpG) oligodeoxynucleotides (ODNs).

Notes: The immunomodulatory cascade triggered by CPG ODNs includes the activation of T helper I (ThI) cells and secretion of proinflammatory cytokines such as interleukin (IL)-6, IL-I2, and interferon gamma (IFN- $\gamma$ ). The CpG motifs in either bacterial DNA or synthetic CpG ODNs act as "danger signals" to the innate immune system, triggering a protective immune response against the pathogen. In addition, the adaptive immune response mounted by the host afterward will maintain an immunologic memory and provide long-lasting protection.

Abbreviation: TNF $\alpha$, tumor necrosis factor-alpha. 
Delivery systems for CpG ODNs using NPs as carriers differ greatly from delivery systems for anticancer drugs and nucleic acid drugs such as antisense DNA and small interfering RNA (siRNA). For delivery of anticancer drugs using NPs, the NPs must be delivered from the bloodstream to the cancerous tissues through vascular walls. Therefore, NPs of around $100 \mathrm{~nm}$ in size are required. Also, manipulation is required so that immune cells do not capture the NPs before they arrive at cancerous tissues. The target cells for the delivery of $\mathrm{CpG}$ ODN, on the other hand, are antigenpresenting cells (APCs) and B cells. These immune cells easily take up relatively large particles, greater than $100 \mathrm{~nm}$ in size. ${ }^{23}$ For delivery of antisense DNA and siRNA, after they have been taken up by cells as a result of endocytosis, their nucleic acids must move from the endosome to the nucleus. However, with the delivery of $\mathrm{CpG}$ ODN, because the receptor TLR9 is localized in the endosome, CpG ODNs must be retained in the endosome for a long period of time. Therefore, delivery systems using $\mathrm{CpG}$ ODNs require a design strategy different from that of conventional drug delivery systems.

This review summarizes the structural features that depend on base sequences of $\mathrm{CpG}$ ODNs consisting of phosphorothioate and phosphodiester backbones and considers their relationship to the capacity of immune mediator cytokine induction. In addition, this review also considers the advantages and disadvantages in a delivery system of these $\mathrm{CpG}$ ODNs using various NPs as carriers and describes the possible future direction of studies on CpG ODNs.

\section{Synthetic CpG ODNs with various structures and their immunostimulatory effect DNase-resisitant CpG ODNs for TLR9 activation}

Because ODNs that contain CpG motifs are quickly degraded by DNase, research has been conducted on CpG ODNs resistant to DNase. ${ }^{24-30}$ DNase-resistant CpG ODNs consisting of a phosphorothioate backbone have been developed by replacing the oxygen in the phosphate group of the nucleic acid targeted by DNase. ${ }^{24,25,31}$ These chemically modified synthetic CpG ODNs are divided into at least four classes (Table 1 and Figure 2).

Class A (also known as type D) CpG ODN has a naturally occurring phosphodiester backbone and palindromic $\mathrm{CpG}$ motifs at the center of its sequence. Poly $(\mathrm{G})$ sequences on phosphorothioate backbones are attached to the $3^{\prime}$ and $5^{\prime}$ ends. ${ }^{32-34}$ This class of CpG ODN activates the TLR9 of pDCs and induces IFN- $\alpha$. However, it almost never induces the multiplication of $B$ cells. The entire sequence of class B (type K) CpG ODN consists of a phosphorothioate backbone. ${ }^{33-36}$ This class of $\mathrm{CpG}$ ODN induces the proliferation and activation of B cells. However, its ability to induce IFN- $\alpha$ with pDCs is low. ${ }^{37}$ Class $\mathrm{C}$ includes

Table I Features of each class of cytosine-phosphate-guanosine (CPG) oligodeoxynucleotides (ODNs)

\begin{tabular}{|c|c|c|c|c|}
\hline & Class A (type D) & Class B (type K) & Class C & Class $\mathbf{P}$ \\
\hline ODN structure & $\begin{array}{l}\text { Central phosphodiester region } \\
\text { containing one or more CpG motifs } \\
\text { in a palindrome and } 5^{\prime} \text { and/or } 3^{\prime} \text { ends } \\
\text { consisting of poly }(\mathrm{G}) \text { motifs with } \\
\text { phosphorothioate backbone }\end{array}$ & $\begin{array}{l}\text { Completely } \\
\text { phosphorothioate backbone }\end{array}$ & $\begin{array}{l}\text { One or more } 5^{\prime} C_{p G} \\
\text { motif(s) and a } \\
3^{\prime} \text { palindrome }\end{array}$ & $\begin{array}{l}\text { Two palindromes consisting } \\
\text { of phosphorothioate backbone }\end{array}$ \\
\hline Examples & $\begin{array}{l}\text { ODN2216 (for human) } \\
\text { ODN2336 (for human) } \\
\text { ODNI585 (for mouse) }\end{array}$ & $\begin{array}{l}\text { ODN2006 (also know as } \\
\text { PF-35I } 2676 \text { and CpG7909, } \\
\text { for human) } \\
\text { ODNI } 668 \text { (for mouse) } \\
\text { ODNI826 (for mouse) }\end{array}$ & $\begin{array}{l}\text { ODN2395 } \\
\text { (for human and mouse) } \\
\text { ODN M362 } \\
\text { (for human and mouse) }\end{array}$ & ODN21798 \\
\hline $\begin{array}{l}\text { Mainly stimulated } \\
\text { cell types }\end{array}$ & pDCs & B cells & pDCs and B cells & $\mathrm{pDCs}$ \\
\hline Actions & $\begin{array}{l}\text { Innate immune responses: } \\
\text { IFN- } \alpha \text {, TNF } \alpha \text {, and IL- } 12 \text { secretion } \\
\text { Adaptive immune responses: } \\
\text { IL-I } 2 \text { and IPI } 0 \text { secretion }\end{array}$ & $\begin{array}{l}\text { Innate immune responses: } \\
\text { IL-6, IL- I0, and } \\
\text { IL- } 12 \text { secretion } \\
\text { Adaptive immune responses: } \\
\text { antibody production; } \\
\text { IL-6 and IL- } 12 \text { secretion }\end{array}$ & $\begin{array}{l}\text { Intermediate between } \\
\text { the } A \text { and } B \text { classes }\end{array}$ & $\begin{array}{l}\text { Potency for IFN- } \alpha \text { secretion } \\
\text { is higher than that of } \\
\text { CpG ODN in class } C\end{array}$ \\
\hline
\end{tabular}

Abbreviations: IFN $\alpha$, interferon-alpha; IL, interleukin; IPI0, interferon-gamma-inducible protein of I0 kDa; pDC, plasmacytoid dendritic cell; TNF $\alpha$, tumor necrosis factor-alpha. 


\section{Class-A ODN2216}

5'-G-G-G-G-G-A-C-G-A-T-C-G-T-C-G-G-G-G-G-G-3'

\section{Class-A ODN2336}

5'-G-G-G-G-A-C-G-A-C-G-T-C-G-T-G-G-G-G-G-G-G-3'

\section{Class-B ODN2006}

5'-T-C-G-T-C-G-T-T-T-T-G-T-C-G-T-T-T-T-G-T-C-G-T-T-3

\section{Class-C ODN2395}

5'-T-C-G-T-C-G-T-T-T-T-C-G-G-C-G-C-G-C-G-C-C-G-3'

\section{Class-P ODN21798}

5'-T-C-G-T-C-G-A-C-G-A-T-C-G-G-C-G-C-G-C-G-C-C-G-3'

Figure 2 Features of cytosine-phosphate-guanosine oligodeoxynucleotide (ODN) sequences in each class.

Note: Underlining indicates palindromic sequence; black and red hyphens indicate phosphodiester and phosphorothioate bonds, respectively.

one or two CpG motif(s) with a phosphodiester backbone at the $5^{\prime}$ end, and contains a palindromic sequence on a phosphorothioate backbone at the $3^{\prime}$ end. This class of $\mathrm{CpG}$ ODN has the capacity to induce the proliferation of $\mathrm{B}$ cells and the production of IFN- $\alpha$ via $\mathrm{pDCs}$; it has a quality between classes A and B. ${ }^{38-41}$ Also, class P CpG ODN has two palindromic motifs on phosphorothioate backbones. It displays a high capacity for producing IFN- $\alpha$ and the ability to activate nuclear factor-kappa B. ${ }^{42}$

These classes of CpG ODN include a complete or partial phosphorothioate backbone, so that they are resistant to DNase. However, side effects are a cause for concern. Reports of side effects include the prolongation of coagulation time due to the inhibition of the tenase complex, ${ }^{43}$ distribution of cell signaling due to nonspecific adsorption of proteins including transcription factors, ${ }^{44}$ and acute toxicity due to complement activation. ${ }^{45,46}$ These classes of CpG ODN have also been reported to cause renal damage. ${ }^{47,48}$ Therefore, ideally, naturally occurring $\mathrm{CpG}$ ODNs consisting only of phosphodiester backbone is desired. Because DNA is mainly decomposed by exonucleases, it is believed that a ring structure like a plasmid is difficult to break down. When DNA with only a phosphodiester backbone was formed into a dumbbell-like structure, it certainly displayed resistance to DNase. ${ }^{49-51}$ Schmidt et al ${ }^{52}$ synthesized an ODN with a phosphodiester backbone in a dumbbell-like structure designed to include $\mathrm{CpG}$ motifs in hairpin-loops (Figure 3A). By utilizing the actions of peripheral blood mononuclear cells, immunostimulatory effects similar to linear-structure $\mathrm{CpG}$ ODNs with phosphorothioate backbones at both ends were obtained. Immunostimulatory activity that induces TNF- $\alpha$ and IL-6 is found in Y-shaped DNA (Y-DNA) itself, formed
A

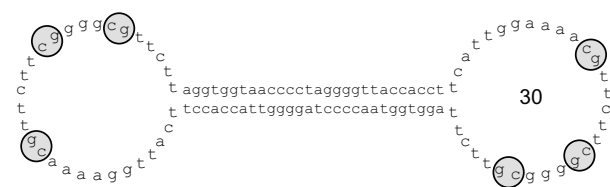

B

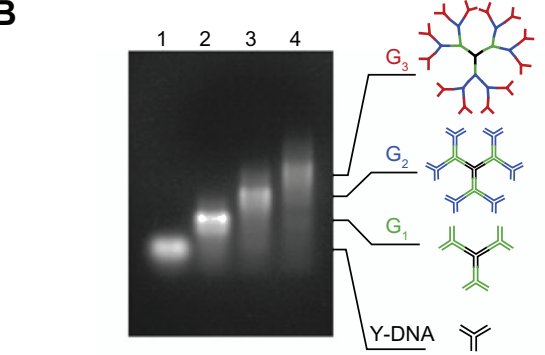

C

CpG-A vogr CPG-B Vagn CPG-C VoGO CPG-D Vogn

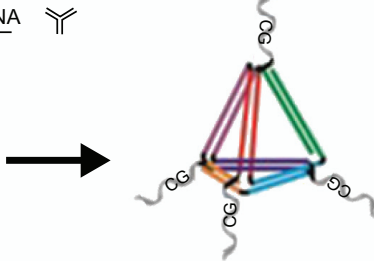

Figure 3 Structures of cytosine-phosphate-guanosine $\left(C_{p} G\right)$ oligodeoxynucleotides (ODNs) consisting of entirely phosphodiester backbone. (A) Sequence and structure of $C_{P G}$ ODN with a dumbbell-like structure: the $C_{P} G$ ODN with a dumbbelllike structure has 30 nucleotides in both loops that contain three $C_{p}$ G dinucleotide motifs. ${ }^{a}$ (B) Structure of dendrimer-like DNA: Y-shaped DNA consists of three single-stranded DNA with 30 nucleotides containing CPG dinucleotide motifs; GI, G2, and G3 dendrimer-like structures were synthesized by ligation of $Y$-shaped DNA; the sizes of CPG ODNs with GI, G2, and G3 dendrimer-like structures were about 12, 20, and $36 \mathrm{~nm}$, respectively. ${ }^{b}$ (C) Assembly of CpG bearing DNA tetrahedral nanostructure: the core tetrahedral nanostructure consists of assembly with four 55-mer ODNs. The CPG motif is linked to each ODN via a 7-mer oligothyamine spacer.

aReproduced with permission from Schmidt et al, ${ }^{52}$ breproduced with permission from Rattanakiat et $\mathrm{a}^{30}$; 'reproduced with permission from Li et al..$^{55}$

from three single-strand DNA having naturally occurring phosphodiester backbones. ${ }^{53}$ DNA with branch structures, like Y-DNA, has outstanding cellular uptake efficiency. However, it has no resistance to DNase. Rattanakiat et $\mathrm{al}^{30}$ discovered that dendrimer-like DNA (DL-DNA) (Figure 3B) with phosphodiester backbones, formed by linking Y-DNA containing $\mathrm{CpG}$ motif, has high immunostimulatory activity. One of the causes of this high activity is believed to be DL-DNA's resistance to DNase. Recently, Nishikawa et al ${ }^{54}$ observed that TNF- $\alpha$ release from RAW264.7 cells at 8 hours after stimulation by $\mathrm{CpG}$ motifs contained X-shaped DNA consisting entirely of phosphodiester backbone. This suggests that X-shaped DNA was stable for 8 hours at least, although Y-DNA has no resistance to DNase. Li et $\mathrm{al}^{55}$ synthesized the CpG-bearing DNA tetrahedral nanostructure with only a phosphodiester backbone (Figure 3C). The core tetrahedral structure comprised four 55-mer ODNs self-assembled with one another by an annealing process. $\mathrm{CpG}$ motif sequence was linked to each ODN via a 7-mer oligothiamine spacer. 
The CpG-bearing DNA tetrahedral nanostructure was efficiently taken up into macrophage-like cells, and induced various pro-inflammatory cytokines such as TNF- $\alpha$, IL-6, and IL-12 through TLR9 activation. Li et $\mathrm{al}^{55}$ also suggested that the stimulatory effect of the tetrahedral nanostructure is due to resistance to DNase, because the tetrahedral nanostructure DNA was stable in serum for 8 hours.

Furthermore, Meng et al ${ }^{56}$ discovered that linearstructured $\mathrm{CpG}$ ODNs consisting only of a phosphodiester backbone possess high TLR9 activation capacity. TLR9 activation by class B ODNs is most optimal when there are two to four CpG motifs. When four or more $\mathrm{CpG}$ motifs were linked, ODN consisting only of a phosphodiester backbone remarkably improved its resistance against DNase. The ODN contained nine or more CpG motifs, remained largely intact in serum for more than 24 hours, and possessed high TLR9 activation capacity even in low concentrations. Because DNA administered inside the body is cleaved from the $3^{\prime}$ end by exonuclease, when the $3^{\prime}$ end of CpG ODN with only a phosphodiester backbone was modified, its resistance to DNase increased. ${ }^{56}$ When multiple $\mathrm{CpG}$ motifs are linked, even when the $3^{\prime}$ end is cleaved by exonuclease, the activation capacity of TLR9 can be maintained when the cell is acted on because many CpG motifs still remain.

\section{Structure-dependent immunostimulatory effect of synthetic CPG ODNs}

Class A CpG ODNs induce the production of IFN- $\alpha$ by activating the TLR9 of pDC. However, class B ODNs do not induce the production of IFN- $\alpha$ via pDCs. This shows that the action of CpG ODNs is dependent on base sequence and structure.

Class A CpG ODNs form nanometer-sized multimers under certain physiological conditions and take on globular and linear structures (Figure 4A). ${ }^{57}$ This globular structure is split into two forks. ${ }^{57,58}$ This is because the structure forms a duplex because of the palindromic sequence of base pairs at the center of the ODN. Next, the four poly $(\mathrm{G})$ sequences at the end of these duplexes combine with one another because of Hoogsteen base pairing and become a G-tetrad structure. As a result, they become G-quadruplex structures (Figure 4B). G-quadruplex can form a linear structure when it further forms a G-tetrad with another duplex (Figure 4B). Also, when two strands of monomeric CpG ODN combine with the G-quadruplex, there is a possibility that two-forked NPs can form (Figure 4C). In other words, class A CpG ODNs spontaneously form higher-order structures because of their palindromic sequence and poly $(\mathrm{G})$. For class A $\mathrm{CpG}$ ODN2216, in the case of linear structure, its length is more than $100 \mathrm{~nm}$, and in the case of globular structure, the maximum

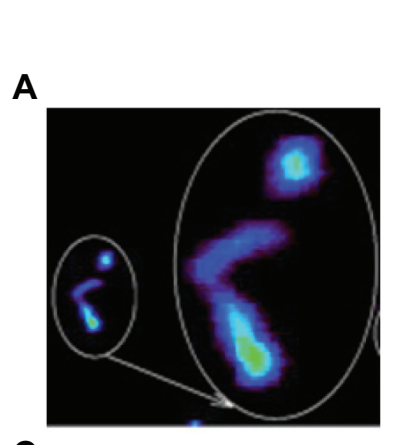

C

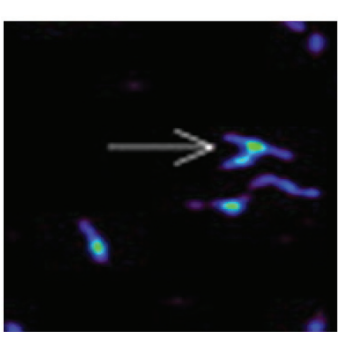

B

\section{Quadruplex}
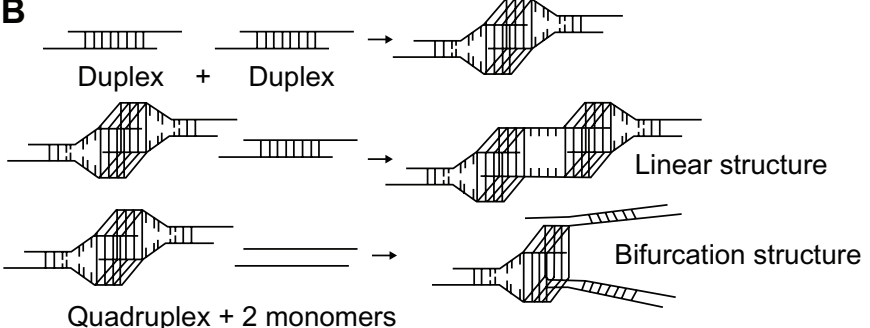

D

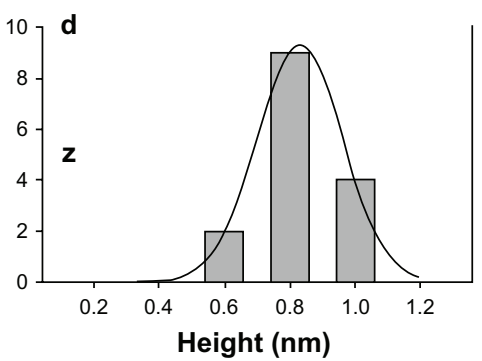

Figure 4 Formation of higher-order structure in class A oligodeoxynucleotides (ODNs). (A) Globular structure of class $A$ cytosine-phosphate-guanosine (CpG) ODN observed by atomic force microscopy (large circled structure is a close-up view of small circle). (B) Possible higher-order structure formation of class A CpG ODNs. Class A CPG ODNs comprise a palindromic sequence in the center and poly $(\mathrm{G})$ sequences at both the $5^{\prime}$ and the $3^{\prime}$ ends. Two monomer molecules form a duplex that is attributed to palindromic sequences. Two duplexes further form a quadruplex through G-tetrad formation of four poly $(G)$ ends. Association of the quadruplex with another duplex causes a linear structure. Two other $C_{P}$ monomers replace the original duplex by forming two new duplexes, which leads to formation of a bifurcation with three ends. (C) A bifurcation structure of class A CPG ODNs imaged by atomic force microscopy. (D) Height histogram of higher-order structure in class A CpG ODNs. Reproduced with permission from Klein et al. ${ }^{58}$ 
size is $50 \mathrm{~nm} \cdot{ }^{57}$ Also, class A CpG ODN2336 has an average height of $0.8 \pm 0.1 \mathrm{~nm}$ (Figure 4D) and length of 30-70 nm. ${ }^{58}$ Meanwhile, such higher-order structures are not observed in class B CpG ODNs; they form a linear structure. ${ }^{58}$

Because poly $(\mathrm{G})$ binds with scavenger receptors on the cell surface, ${ }^{59}$ ODNs that contain poly $(\mathrm{G})$ sequences have been reported to show an increase in cellular uptake efficiency. ${ }^{34,60}$ This suggests that the high cellular uptake efficiency of class A CpG ODNs with poly $(G)$ also means a high TLR9 activation capacity. On the other hand, Kerkmann et $\mathrm{al}^{57}$ reported that the cellular uptake efficiency of class $\mathrm{A}$ and class $\mathrm{B} \mathrm{CpG}$ ODNs did not change. They suggested that the greater ability of class A CpG ODNs to produce IFN- $\alpha$ than class $\mathrm{B} \mathrm{CpG}$ ODNs is because of the higher-order structure of class A CpG ODNs. This is because when the palindromic sequence is changed, higher-order structures are not formed, and the ability to produce to IFN- $\alpha$ is decreased. Furthermore, it has been observed that when class B CpG ODNs were loaded onto polystyrene NPs $180 \mathrm{~nm}$ in diameter, their production capacity of IFN- $\alpha$ was greater than that of class A CpG ODNs. ${ }^{57}$ Because the cellular uptake efficiency of free class B CpG ODNs loaded onto polystyrene NPs do not change, it is believed that the high IFN- $\alpha$ production capacity of class A CpG ODNs is due to its spontaneously formed higher-order structure. Other research groups have reported that by artificially causing class $\mathrm{B} \mathrm{CpG}$ ODNs to form higher-order structures using NPs, an immune profile similar to class A CpG ODNs could be obtained. ${ }^{61-63}$ Class $\mathrm{C}$ $\mathrm{CpG}$ ODNs also form a duplex, because of the palindromic sequence at the $3^{\prime}$ end. This structure is believed to affect the activation of TLR9.

Naturally occurring DL-DNA containing CpG motifs synthesized as Y-DNA structural units displayed high immunostimulatory activity. ${ }^{30}$ The hydrodynamic size of Y-DNA formed from three-strand 30-base ODN was $7.0 \pm 0.2 \mathrm{~nm}$; however, second- and third-generation DL-DNA (Figure 3B) were $20 \pm 1.2 \mathrm{~nm}$ and $35.8 \pm 3.2 \mathrm{~nm}$, respectively. Receptor-mediated endocytosis is dependent on the size of ligands, and the optimal size for uptake is known to be $25-30 \mathrm{~nm} \cdot{ }^{64-67}$ The size of DL-DNA falls within this range, so its high immunostimulatory activity may have an effect on cellular uptake efficiency in addition to resistance to DNase. What is extremely interesting is that Y-DNA has immunostimulatory activity even if it does not contain $\mathrm{CpG}$ motifs. ${ }^{54}$ This suggests the importance of the higher-order structure of ODNs on immunostimulation.

Meng et $\mathrm{al}^{56}$ reported that ODNs consisting only of a phosphodiester backbone and linked with numerous
CpG motifs exhibited high TLR9 production capacity. CpG ODN2006, a class B prototype, includes three CpG motifs. PD-ODN2006 is synthesized with a phosphodiester backbone, not the phosphorothioate backbone of the original ODN2006 sequence, and it has no TLR9 activation capacity because DNase degrades it. PD-ODN2006-2006, composed of two PD-ODN2006s linked together, is not degraded much by DNase and possesses high TLR9 activation capacity (Figure 5). When the size of the DNA is below 250 bases, cellular uptake efficiency increases as the DNA size increases. ${ }^{68}$ However, a sequence that indirectly connects PD-ODN2006s using a 14-mer ligand sequence without a CpG dinucleotide sequence (PD-2006-linker-2006) showed lowered TLR9 activation capacity (Figure 5). PD-ODN20062006 and PD-ODN2006-linker-2006 both contain six CpG motifs. The difference in TLR9 activation capacity despite this characteristic suggests that aside from the number of CpG motifs and size, TLR9 activation is also dependent on the ODN sequence.

\section{Delivery of CpG ODNs using NPs}

Control of the immune system via TLR9 by CpG ODNs has been shown to be effective for treating infectious diseases, cancers, and allergies. In recent years, various NPs have been developed as carriers of CpG ODNs. The number of papers related to the delivery of $\mathrm{CpG}$ ODNs using NPs has increased sharply since 2007.

The advantages of using NPs as $\mathrm{CpG}$ ODN carriers include (1) protection from DNase degradation, (2) extension of retention time inside the body, (3) decrease in the amount administered because cellular uptake efficiency is improved, (4) the ability to change the structure of CpG ODNs, (5) the ability to deliver to target tissues, (6) the ability to change localization inside the body, and (7) allow the slow release of $\mathrm{CpG}$ ODNs over a long period of time.

\section{Protection of CpG ODNs from degradation by DNase}

Concerning the protection of $\mathrm{CpG}$ ODNs from DNase by NPs, many research studies use $\mathrm{CpG}$ ODNs with a phosphorothioate backbone resistant to DNase, so there is little direct evidence available. Because antisense ODNs encapsulated by cationic lipid NPs or lipid NPs have been reported to be partially or completely protected from DNase degradation in serum, ${ }^{69,70} \mathrm{CpG}$ ODNs with only phosphodiester backbone are believed to have similar effects when encapsulated by these nanopaNPsrticles. Zhu et $\mathrm{al}^{71}$ showed that CpG ODNs with only a phosphodiester backbone 
A

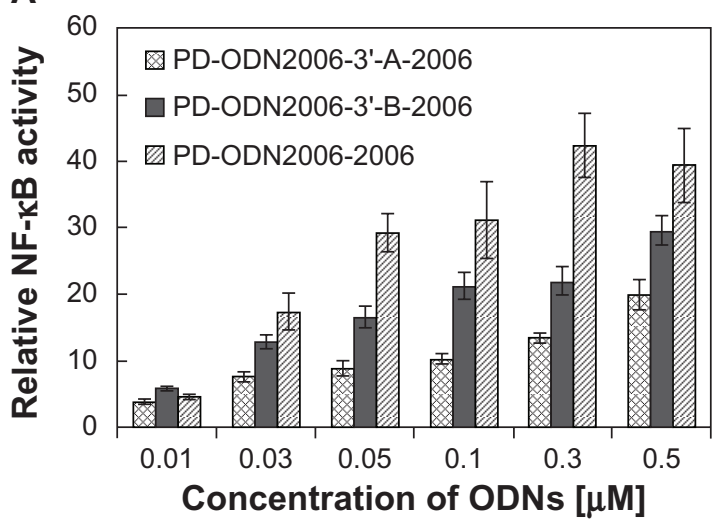

B

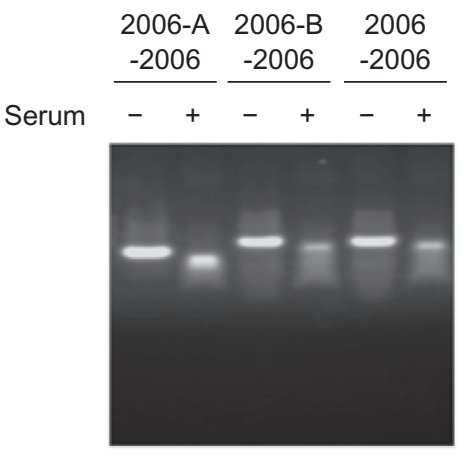

Figure 5 Effect of linker sequences in phosphodiester (PD) cytosine-phosphate-guanosine (CPG) oligodeoxynucleotide 2006 (ODN2006) connection on Toll-like receptor 9 (TLR9) activation. ${ }^{a}$ (Original ODN2006 consists entirely of phosphorothioate backbone, but the backbones of all the CpG ODNs used in this experiment were replaced by naturally occurring phosphodiester bonds.) (A) Activation of TLR9 represented by nuclear factor-kappa B (NF-KB) activity: $293 \mathrm{XL}-\mathrm{hTLR} 9$ cells were stimulated by series connection of PD-ODN2006 with and without linker sequences. PD-ODN2006-2006, composed of two phosphodiester ODN2006s directly linked together, showed higher capacity for TLR9 activation than PD-ODN2006-A-2006 and PD-ODN2006-B-2006, whose sequences consist of indirectly connected phosphodiester ODN2006s using 14-mer linkers (sequence of linker A, CCTTCAGTGGGACC; sequence of linker B, GGTCCCACTGAAGG). (B) Stability of these CPG ODNs consisting of entirely phosphodiester backbone in solution with and without serum imaged by gel electrophoresis: these CPG ODNs consisting entirely of phosphodiester backbone were resistant to deoxyribonuclease in serum.

Notes: ${ }^{a}$ The sequence of ODN2006 that contains three $C_{p}$ G motifs is shown in Figure 2.

Reproduced with permission from Meng et al. ${ }^{56}$

joined electrostatically to the surface of NPs acquired resistance to DNase degradation. They observed that all molecules of $\mathrm{CpG}$ ODNs with a completely phosphodiester backbone were broken down within an hour in $20 \%$ serum. However, $\mathrm{CpG}$ ODNs attached electrostatically to mesoporous silica NPs, the surface of which were modified with amino groups, remained after 3 hours without being degraded (Figure 6). Furthermore, when the conjugate of these NPs and CpG ODNs was coated with poly(allylamine hydrochloride), the efficiency of protection against DNase was discovered to increase. In vivo mice experiments have

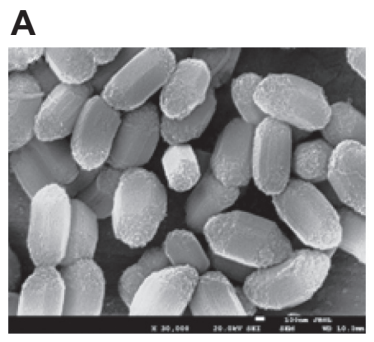

B

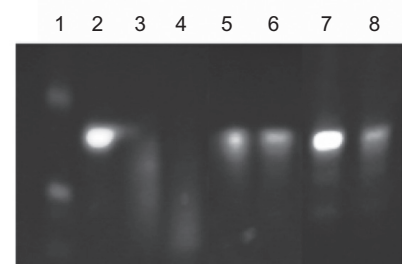

Figure 6 Mesoporous silica nanoparticles (NPs) for delivery of natural cytosinephosphate-guanosine ( $\mathrm{CPG}$ ) oligodeoxynucleotides (ODNs) consisting entirely of phosphodiester backbone. (A) Scanning electron microscopic image of aminomodified mesoporous silica SBA-I5 particles. (B) Stability of CPG ODNs consisting entirely of phosphodiester backbone in $20 \%$ serum containing medium: lane I, DNA marker; lane 2, undigested CPG ODN consisting entirely of phosphorothioate backbone; lanes 3 and 4, free natural CPG ODN after incubation for I and 3 hours; lanes 5 and 6, natural $C_{p G}$ ODN loaded on mesoporous silica NPs after incubation for $I$ and 4 hours; and lanes 7 and 8 , natural CPG ODN loaded on mesoporous silica NPs followed by polycation (poly(allylamine hydrochloride)) treatment after incubation for I and 3 hours. This indicates that natural CPG ODN consisting entirely of phosphodiester backbone loaded on mesoporous silica NPs was stable in serum. Reproduced with permission from Zhu et al. ${ }^{71}$ shown that $272 \mathrm{~nm}$ cationic poly(D,L-lactic-co-glycolic acid) (PLGA) NPs were taken up into pDCs in less than an hour, ${ }^{72}$ so that protection of $\mathrm{CpG}$ ODNs against DNase by NPs for several hours is considered to be sufficient. The greatest advantage of using NPs is protection against DNase, as $\mathrm{CpG}$ ODNs consisting of chemically unmodified phosphodiester backbone can be used.

\section{Prolonged circulation time and increased cellular uptake}

In vivo experiments have reported that NPs prolong the circulation lifetime of $\mathrm{CpG}$ ODNs in the body. Pan et $\mathrm{al}^{73}$ included a CG sequence in an 18-mer antisense ODN for controlling the Bcl-2 gene and discovered that this could activate the immune system. When free antisense ODN with phosphorothioate backbone was administered intravenously to mice, only $1 \%$ remained in plasma after 24 hours. When this antisense ODN was encapsulated in lipid NPs (89 $\pm 45 \mathrm{~nm}$ in diameter) composed of $3 \beta-[N, N-$ (dimethylaminoethane)carbamoyl] cholesterol (DC-Chol), egg yolk phosphatidylcholine, distearoylphosphatidylethano lamine- $N$-[methoxy(polyethylene glycol)-2000] ( $\mathrm{mPEG}_{2000^{-}}$ DSPE), and protamine, $25 \%$ of the ODN remained in plasma after 24 hours. This shows that encapsulation in lipid NPs extends blood circulation time. DC-Chol, a cationic lipid, partially deprotonates in near-neutral $\mathrm{pH}$ and decreases the surface electrical charge of NPs. Also, $\mathrm{mPEG}_{2000}$-DSPE on the surface of NPs decreases the uptake of NPS by 
the reticuloendothelial system. These actions are believed to prolong the blood circulation time. When this lipid NP-encapsulated antisense ODN was administered, the cumulative dose to tumorous tissues was about nine times that of free ODN. Traditional cationic lipid NPs are quickly eliminated from the circulatory system, ${ }^{45}$ but if the electrical charge on the NPs' surface is reduced, as in the case of DC-Chol, circulation time can be extended. Wilson et $\mathrm{al}^{27}$ discovered neutral cationic lipid NPs ionizable at physiological $\mathrm{pH}$. When ionizable cationic lipid NPs and ODN are mixed under a low $\mathrm{pH}$ condition, the surface of the NPs becomes charged, and the ODN is electrostatically attached. Next, when these NPs are transferred to $40 \%$ ethanol, the structure of the NPs becomes unstable and ODN is taken up into the interior of the NPs. Afterwards, when the $\mathrm{pH}$ is made neutral, the NPs become neutral NPs. In contrast to the free ODN circulation lifetime of a few minutes, the circulation lifetime of ODN encapsulated in ionizable cationic lipid NPs can be extended from several hours to several days. ${ }^{74,75}$

One of the reasons that CpG ODNs adsorbed into NPs or with encapsulated phosphorothioate backbone show greater TLR9 activity than free CpG ODNs is that the cellular uptake efficiency of $\mathrm{CpG}$ ODNs is improved. The cellular uptake efficiency of $\mathrm{CpG}$ ODNs is being studied using fluorescently labeled $\mathrm{CpG}$ ODNs. When fluorescently labeled free $\mathrm{CpG}$ ODN was added to cultured 239XL-TLR9 cells, fluorescence was not observed inside the cells. In contrast, strong fluorescence was observed in CpG ODN adsorbed by mesoporous silica NPs and boron nitride NPs (Figure 7). ${ }^{71,76}$ In vivo studies have shown the method of delivering $\mathrm{CpG}$ ODN using lipid NPs significantly increased uptake efficiency

A

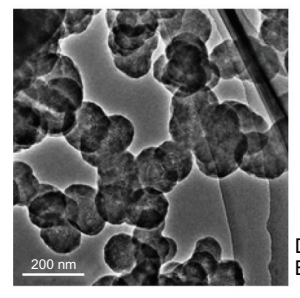

B

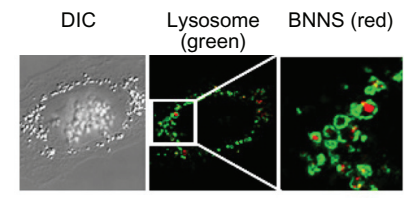

C

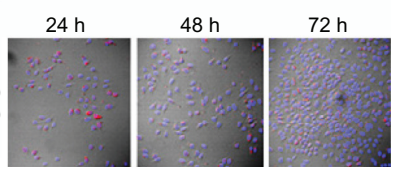

Figure 7 Boron nitride nanospheres (BNNSs) as carrier for cytosine-phosphateguanosine oligodeoxynucleotide delivery: (A) transmission electron microscopic image of BNNSs; (B) localization of BNNSs taken up into cell (BNNSs [red] are localized in endolysosome [green]); (C) distribution of BNNSs during cell proliferation. Cells and BNNS were stained with DAPI (blue) and rhodamine B (red), respectively. BNNSs (red) were observed even in divided cells that were incubated for 48 and 72 hours (h).

Reproduced with permission from Zhi et al. ${ }^{76}$

Abbreviation: DIC, differential interference contrast. compared with free $\mathrm{CpG}$ ODN when it was administered to mice and the uptake into APCs in the spleen and lymph nodes was observed after 24 hours. ${ }^{27}$ Also, when CpG ODNs were loaded onto cationized gelatin NPs with an average diameter of $272 \pm 33.3 \mathrm{~nm}$, after 2 days DCs in draining lymph nodes were $30 \% \mathrm{CpG}$ positive and B cells were $20 \%$ positive. ${ }^{77}$ The cause is believed to be the increase in the delivery efficiency of $\mathrm{CpG}$ ODNs by NPs, with many $\mathrm{CpG}$ ODNs being adsorbed or encapsulated per NP. Klier et $\mathrm{al}^{78}$ also reported that class $\mathrm{A} \mathrm{CpG}$ ODN delivered by gelatin NPs showed significant immunomodulation effect (Th2/ Th1 shift) on equine bronchoalveolar lavage cells. This effect is believed to be an enhancement of cellular uptake of $\mathrm{CpG}$ ODNs by gelatin NPs.

Clathrin-mediated endocytosis, caveolae-mediated uptake, phagocytosis, macropinocytosis, and clathrin- and caveolae-independent endocytosis are all possible methods for the uptake of lipid NPS into cells. The specific method depends on the type of cells. ${ }^{27}$ When free CpG ODNs were charged negatively, it was difficult for them to attach to a negatively charged cell surface. This electrostatic repulsion is believed to limit the efficiency of free CpG ODN uptake.

The size of NPs affects both cellular uptake and TLR9 activation. Foged et $\mathrm{al}^{23}$ investigated phagocytic activity on DCs by polystyrene NPs of various sizes from 0.04 to $15 \mu \mathrm{m}$, and reported that the size of $500 \mathrm{~nm}$ was optimal for uptake into DCs. Also, when the NP size was greater than $200 \mathrm{~nm}$, it was reported that the retention time in the endosome was long. However, NPs form aggregates or agglomerates in solution. When NPs form aggregates or agglomerates, cells take in not only NPs by themselves but also NPs in aggregates or agglomerates. Therefore, not the primary size of NPs but their hydrodynamic size should be used as the indicator of the effects of the size of NPs on cellular uptake.

\section{Retention of NPs loaded with CpG ODNs in endolysosome}

TLR9 joins with CpG ODNs in the endolysosome; therefore, it is important to retain the $\mathrm{CpG}$ ODN in the endolysosome. Vectors and siRNA delivery systems must deliver to the nucleus; therefore, breaking out from the endolysosome is necessary. However, for the delivery systems of CpG ODNs, because TLR9 exists in the endolysosome, breaking out from the endolysosome is not necessary but staying in is. Chen et $\mathrm{al}^{79}$ coated the surface of polystylene NPs with four types of cationic polymers - poly(ethylenimine), chitosan, poly(2-dimethyl-amino)ethyl methacrylate, and poly(Llysine) - to cause $\mathrm{CpG}$ ODN to bind. They reported that 
with poly(L-lysine), there was least escape of NPs from the endolysosome. This means that the type of polycation has an effect on the retention of NPs in the endosome. When Zhi et $\mathrm{al}^{76}$ added boron nitride NPs to 293XL-TLR9 cells, it was localized in the lysosome after 24 hours. This localization was maintained even after the cell division (Figure 7).

\section{Sustained release of CpG ODNs}

The increase in uptake efficiency of $\mathrm{CpG}$ ODNs and in their efficiency of delivery means that the dose of $\mathrm{CpG}$ ODN can be decreased. Furthermore, the retention of NPs in the endolysosome and lysosome leads to continuous effects by $\mathrm{CpG}$ ODN. Furthermore, the sustained release of $\mathrm{CpG}$ ODN by NPs also results in decreased dosage and continuous effects. Sokolova et $\mathrm{al}^{80}$ prepared multishell NPs that causes CpG ODN to be adsorbed to calcium phosphate (Figure 8). By using a multishell structure, CpG ODN can be protected from DNase. At the same time, calcium phosphate gradually dissolves in the acidic environment of the lysosome's interior, so the slow release of $\mathrm{CpG}$ ODN can be expected. Zhu et al ${ }^{81}$ have
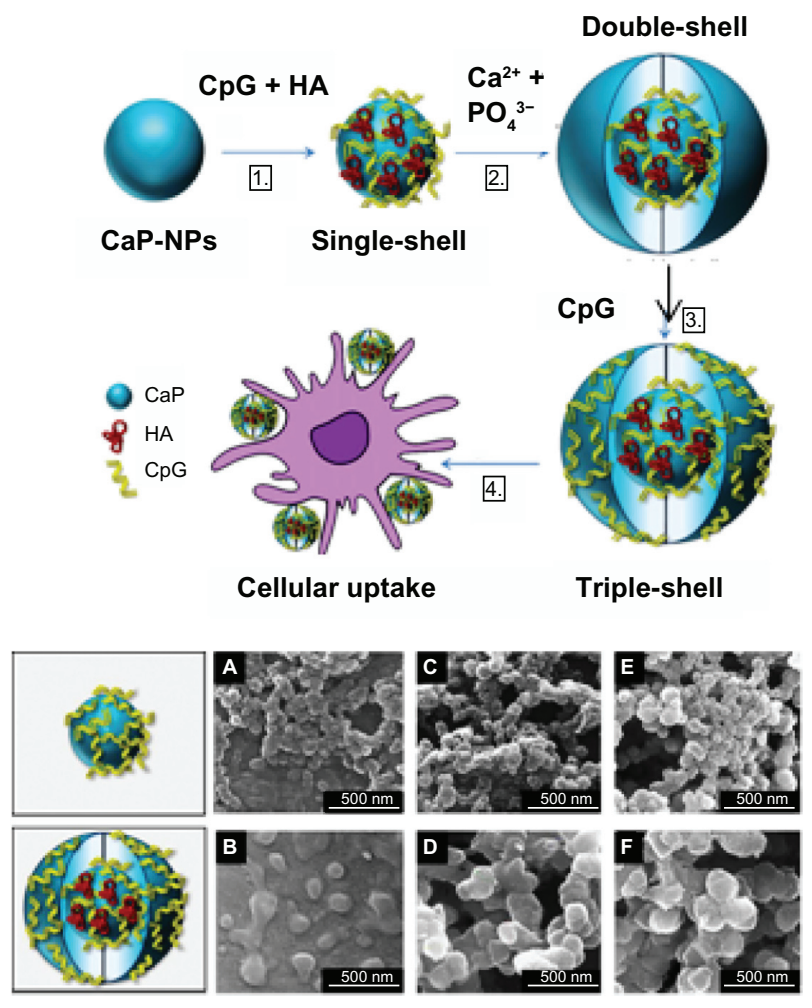

Figure 8 Multishell calcium phosphate (CaP) nanoparticles (NPs) for cytosinephosphate-guanosine (CPG) delivery: (A) preparation of multishell CaP-NPs functionalized with $C_{p G}$ oligodeoxynucleotides and antigen (hemagglutinin, HA): (B) scanning electron micrographs of singe-shell (top panels) and triple-shell NPs (bottom panels).

Reproduced with permission from Sokolova et al. ${ }^{80}$ reported on the enzyme-triggered sustainable release of CpG ODNs. They caused naturally occurring CpG ODN to be adsorbed by hollow mesoporous silica NPs with a laminated surface. Furthermore, they coated the surface with poly(L-lysine). By repeating the adsorption of this CpG ODN and poly(L-lysine), a layer-by-layer adsorption can be formed. By dissolving the NP surface of ploy(Llysine) with $\alpha$-chymotrypsin, $\mathrm{CpG}$ ODN together with low-molecular-weight compounds loaded in the hollow NPs can be slowly released (Figure 9). Demento et $\mathrm{al}^{72}$ controlled the rate of release of $\mathrm{CpG}$ ODN from NPs by attaching biotinylated $\mathrm{CpG}$ ODN to the surface of PLGA NPs modified with avidin-palmitate. Usually $100 \mu \mathrm{g}$ of CpG ODN is administered per mouse, but with NPs, effects were observed with administration of $0.5 \mu \mathrm{g}$. By minimizing the release of $\mathrm{CpG}$ ODN, side effects including autoimmunity and lymphoid architectural damage that occur when $\mathrm{CpG}$ ODN is given in large amounts can be decreased..$^{22}$

\section{Delivery of CpG ODNs to target tissues}

Bourquin et $\mathrm{al}^{77}$ reported that $\mathrm{CpG}$ ODN loaded on cationized gelatin NPs had remarkably high antitumor effects compared with free $\mathrm{CpG}$ ODN in a mouse melanoma model. They investigated the localization of $\mathrm{CpG}$ ODN in vivo, and revealed that while free $\mathrm{CpG}$ ODN accumulated in splenocytes, CpG ODN delivered by NPs was selectively stored in APCs inside draining lymph nodes. The activation of adaptive immune response due to the selective transport to APCs inside draining lymph nodes by NPs is believed to be the cause for the high antitumor effect.

The size of NPs also has an effect on transferability into tissues. The molecular weight of drugs and the size of NPs are known to be factors determining the transferability into lymph nodes. Drugs with a molecular weight less than 5000 injected intramuscularly or subcutaneously are absorbed by capillaries and circulated. However, drugs with a molecular weight greater than 20,000 mainly transfer to lymph nodes. ${ }^{82}$ The commonly used class B CpG ODN with phosphorothioate backbone has a molecular weight of about 8000, and its transferability to lymph nodes is low. For therapeutic NPs administered into the abdominal cavity of mice, it has been reported that NPs with sizes of 100-200 nm are excellent for transferring to lymph nodes and in retention. ${ }^{83}$ Kuramoto et a ${ }^{84}$ prepared liposomes $100-200 \mathrm{~nm}$ in size composed of $N$-[1-(2,3-dioleyloxy)propyl]- $N, N, N$-trimethylammonium chloride, a cationic lipid, and cholesterol, to which $\mathrm{CpG}$ ODNs were loaded. When these NPs were administered to 
A

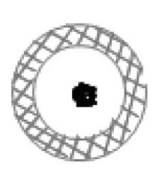

Fluorescein loading

APTES modification

. Fluorescein

ff. Poly-L-Lysine

ऊँj CpG ODN

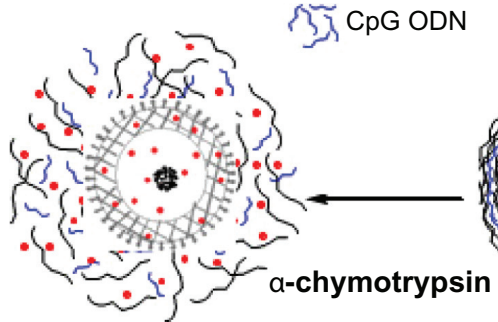

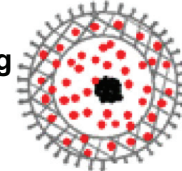

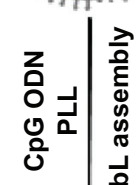

B

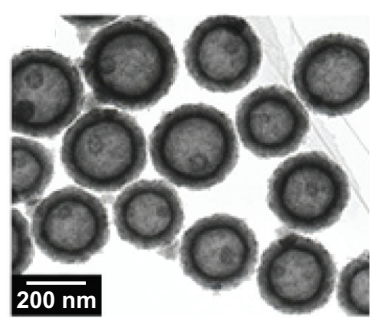

C

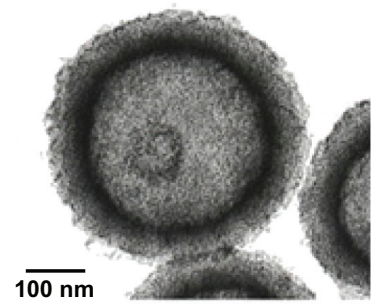

Figure 9 Hollow mesoporous silica/poly(L-lysine) (HMS/PLL) nanoparticles for codelivery of drug and cytosine-phosphate-guanosine (CpG) oligodeoxynucleotides (ODNs): (A) preparation of the fluorescein and CPG ODN-loaded HMS/PLL particles and enzyme triggered release; (B and $\mathbf{C})$ transmission electron microscopic images of HMS nanoparticles.

Reproduced with permission from Zhu et al. ${ }^{81}$

Abbreviations: APTES, aminopropyltriethoxysilane; LBL, layer-by-layer.

the abdominal cavity of mice with peritoneal dissemination, a pronounced antitumor effect was observed compared with CpG ODN alone.

By attaching specific ligands to the surface of NPs, it is possible to deliver them to target cells. Because macrophages and pDCs, which are target cells of CpG ODN, have mannose receptors, it is believed that introducing mannose to the surface of NPs can intensify the effects of CpG ODNs. Kuramoto et al ${ }^{85}$ loaded $\mathrm{CpG}$ ODN on mannose-modified liposome, the surface of which was modified with mannosemodified cholesterol derivative cholesten-5-yloxy-N-(4-((1amino-2- $\beta$-D-thiomannosylbutyl)amino)alkyl)formamide, and administered it to the abdominal cavity of mice with peritoneal dissemination. As a result, by targeting the immune cells in the greater omentum and the mesentery, where numerous lymph nodes exist, increased antitumor effect was reported. Also, Chen et a ${ }^{86}$ synthesized glycodendrimers with terminals consisting of $\alpha$-mannose and made this adsorb to the surface of boron nitride nanotubes. Because $\alpha$-mannnose binds with the mannose receptor of macrophages, $\mathrm{CpG}$ ODN delivered by these NPs is selectively taken up into macrophages. Also, because glycodendrimer is recognized by lectins on the cell surface, cellular uptake efficiency can also be expected to increase.

\section{Multicomponent delivery system including CpG ODNs}

When antigens and $\mathrm{CpG}$ ODNs are delivered at the same time, the advantages of both agents can be maximally drawn out. ${ }^{87,31}$ Furthermore, when delivering these agents simultaneously with NPs, it has been reported that using separate NPs to deliver each of the agents results in greater immunostimulatory effect ${ }^{88-91}$ This suggests that delivering antigens and CpG ODN to APCs at the same time is important.

Standley et $\mathrm{al}^{29}$ encapsulated ovalbumin (OVA), and furthermore prepared acid-degradable NPs (CpG-OVA-NPs) based on a cross-linked polymer network that includeed $\mathrm{CpG}$ ODN. The size of these NPs was 200-500 nm, and the bonding amount of the encapsulated OVA and CpG ODN were 40 and $25 \mu \mathrm{g} / \mathrm{mg}$ NPs for CpG ODN. In vitro assays showed CpG-OVA-NPs increased the amount of IL-12 secreted by APCs by 45 times compared with NPs encapsulating only OVA. Also, the induction of CD40, CD80, and CD86, indicators of DC activation also increased. However, co-delivery had no effect on major histocompatibility complex (MHC) I and MHC II. It has been reported that for in vivo assays, co-delivery can induce OVA-specific CD8 T-cell response. Lee et a ${ }^{12}$ also showed the enhancement of MHC-restricted presentation of antigen by using biodegradable PLGA NPs loaded with CpG ODNs and OVA. Similar profound augmentation of anti-OVA-specific immune response was observed by co-delivery of OVA and $\mathrm{CpG}$ ODN using nanoliposomes. ${ }^{93}$

Nasal and intradermal vaccination is an attractive strategy for CpG ODN delivery. For this strategy in previous studies, mucoadhesive $N$-trimethyl chitosan NPs loaded with OVA and CpG ODN were prepared. ${ }^{94,95}$ This delivery system induced a significantly higher level of IgG2a and increased the number of 
OVA-specific IFN- $\gamma$ producing T cells in the spleen compared with NPs with only OVA, suggesting that the co-delivery of antigen and CpG ODN improves the immunostimulatory effect.

Many studies have reported on systems that incorporate CpG ODN and antigens in biodegradable NPs. ${ }^{96-101}$ These systems co-encapsulate $\mathrm{CpG}$ with antigens in biodegradable NPs. Demento et $\mathrm{al}^{72}$ minimized the release rate of $\mathrm{CpG}$ ODN by using biotin-avidin binding to attach $\mathrm{CpG}$ ODN to the surface of biodegradable PLGA NPs. CpG ODN-modified antigen-encapsulating PLGA NPs that encapsulated antigen peptides of the West Nile virus envelope protein were prepared. The average size of these NPs was $272 \mathrm{~nm}$, and the encapsulated antigen peptides were about $4.7 \mu \mathrm{g} / \mathrm{mg}$ NPs. These NPs were administered to mice, and their immunostimulatory effect was compared with Alhydrogel, which includes antigens and aluminum hydroxide (as adjuvant). The results showed that with Alhydrogel, the level of IgG1, associated with Th2-skewed response, was high. With CpG ODNmodified antigen-encapsulating PLGA NPs, the levels of IgG2a and IgG2b, involved in Th1-based response, were high. Concerning infection of the West Nile virus, the test group administered Alhydrogel had a $44 \%$ survival rate. The test group administered CpG ODN-modified antigenencapsulating PLGA NPs had a 94\% survival rate.

Intratumoral injection of PEGylated unilamellar liposomes bearing surface-conjugated anti-CD40 antibody and CpG ODN has demonstrated synergistic antitumor effects without dose-limiting inflammatory toxicity. ${ }^{102}$ In addition, co-delivery of polyriboinosinic-polyribocytidylic acid (poly(I:C)), an agonist of CpG and TLR3, with CD40 ligand (CD40L), has been reported to intensify the antitumor effect of CD40L. ${ }^{103}$ When vector-expressing CD40L (pSP-DCD40L) was directly administered to mouse tumor together with CpG ODN and poly(I:C), antitumor activity was displayed. When pSP-D-CD40L was loaded onto poly $(\beta$-amino esters), a cationic polymer, and polyethylenimine NPs, and delivered together with $\mathrm{CpG}$ ODN and poly(I:C), even greater antitumor effect was obtained. Wells et al ${ }^{104}$ observed high antitumor activity as a result of the delivery of antiCD40 antibody together with $\mathrm{CpG}$ ODN, poly(I:C9), and IFN- $\gamma$ in an emulsion of squalene and Tween 80 . These high antitumor activities are believed to be due to the induction of the powerful antitumor response of CD8-positive T cells by the stimulation of CD40 combined with TLR agonists. Also, Sokolova et $\mathrm{al}^{80}$ reported that $\mathrm{CpG}$ ODN and poly(I:C) incorporated with hemagglutinin, a model antigen, into multishell calcium phosphate NPs and administered to DCs resulted in a greater amount of IL-12 produced.

\section{Disadvantages of delivery system}

Meanwhile, the disadvantages of using NPs include not being able to establish the safety of NPs and not being able to clarify the metabolic process. When mixed with DNA, cationic polymers like poly(L-lysine) and polyethyleneimine form polyplexes. ${ }^{105-107}$ Also, the method to attach CpG ODN by modifying negatively charged NPs with polycation is the most generally implemented method. However, polycations elicit the nonspecific adsorption of negatively charged molecules, and also promote the formation of NP aggregates. ${ }^{108-110}$ These results are believed to be causes of side effects. Furthermore, it has been suggested that polycations may cause damage to liver from complement activation. ${ }^{45}$ Research has been conducted to avoid these disadvantages of polycations by using PEG $^{111}$ and polyanions. ${ }^{112,113}$ Also, it has been reported that ionizable cationic liposome eliminates these disadvantages of polycations. ${ }^{27} \mathrm{Kim}$ et $\mathrm{al}^{110}$ prepared amphiphilic NPs composed of hydrophilic poly $(\gamma$-glutamic acid) $(\gamma$-PGA) and hydrophobic L-phenylalanine. These NPs are negatively charged by ionizing the carboxyl group near the surface of $\gamma$-PGA. ${ }^{114}$ However, it has been reported that free CpG ODN of the same negative charge can be encapsulated. Forming a polyplex of $\mathrm{CpG}$ ODN and poly( $(\varepsilon-l y s i n e)$, the $\mathrm{CpG}$ ODN load can be increased by encapsulating the polyplex in $\gamma$-PGA and hydrophobic L-phenylalanine.

\section{Prospects for the future}

Recently, a cytosolic DNA-sensing receptor that functions upstream of the TLR was discovered and named the highmobility group box (HMGB) protein. ${ }^{115}$ In addition to being expressed in immune cells, HMGB protein can be found in a variety of other cell types. The protein can recognize DNA and RNA and activate the innate immune system. Furthermore, since HMGB recognizes mammalian DNA, it is thought to be implicated in autoimmune diseases. Class B CpG ODNs with a phosphorothioate backbone demonstrated a high affinity to $\mathrm{HMGB},{ }^{115}$ whereas interaction was not seen with a natural $\mathrm{CpG}$ ODN with a phosphodiester backbone. ${ }^{116}$ These results suggest that CpG ODNs with a phosphorothioate backbone activate innate and adaptive immune systems in B cells and APCs via TLR9, and inhibit the innate immune system in other types of cells. Conversely, natural CpG ODNs with only a phosphodiester backbone activate the innate and adaptive immune systems in B cells and APCs via TLR9 and do not inhibit the innate immune system in other types of cells. From the standpoint of improvement and maintenance of systemic immune activation, the presence of natural $\mathrm{CpG}$ ODNs with a phosphodiester backbone is therefore more 
advantageous than $\mathrm{CpG}$ ODNs with a phosphorothioate backbone.

The number of natural CpG ODNs consisting entirely of phosphodiester backbone developed is significantly smaller than that of $\mathrm{CpG}$ ODNs with a phosphorothioate backbone. The development of clinically applicable natural CpG ODNs is therefore expected to grow in the future. On the other hand, since $\mathrm{CpG}$ ODNs with a phosphorothioate backbone demonstrate high affinity with HMGB protein, they may be effective in the treatment of HMGB-mediated autoimmune diseases ${ }^{116}$ such as rheumatoid arthritis and systemic lupus erythematosus.

There are many benefits of NP-mediated delivery of $\mathrm{CpG}$ ODNs. The author found that the binding modes of $\mathrm{CpG}$ ODNs to NPs affect the production of immune mediators (cytokines) (unpublished data). That is, the type of the binding mode of class B CpG ODNs to NPs can induce the production of either IL-6 or IFN- $\alpha$. This ability to control cytokine induction opens the possibility of treatment-specific preparations of $\mathrm{CpG}$ ODN carriers. Most CpG ODN NP preparations employ $\mathrm{CpG}$ ODNs with a phosphorothioate backbone. As described earlier in this review, natural $\mathrm{CpG}$ ODNs do not require encapsulation in NPs such as liposomes to be protected from DNase activity: adsorption to NPs is sufficient. The development of safe delivery systems for natural $\mathrm{CpG}$ ODNs in NPs is fast approaching.

\section{Conclusion}

The application of $\mathrm{CpG}$ ODNs for the treatment of cancers, infectious diseases, and allergies holds great promise, because CpG ODNs interact with TLR9 and activate both the innate and the adaptive immune system. This review paper summarizes the structural features that depend on base sequences of $\mathrm{CpG}$ ODNs consisting of phosphorothioate and phosphodiester backbones, and their relationship to the capacity of immune mediator cytokine induction. In addition, advantages and disadvantages in the delivery system of these CpG ODNs using various NPs and future direction of studies on $\mathrm{CpG}$ ODNs are described.

The number of natural CpG ODNs consisting entirely of phosphodiester backbone developed is significantly smaller than that of CpG ODNs with a phosphorothioate backbone. The development of clinically applicable natural $\mathrm{CpG}$ ODNs is therefore expected to grow in the future. From the standpoint of improvement and maintenance of systemic immune activation, the presence of natural CpG ODNs with a phosphodiester backbone is therefore more advantageous than $\mathrm{CpG}$ ODNs with a phosphorothioate backbone.
However, since $\mathrm{CpG}$ ODNs with a phosphorothioate backbone demonstrate high affinity with HMGB protein, they may be effective in the treatment of HMGB-mediated autoimmune diseases ${ }^{116}$ such as rheumatoid arthritis and systemic lupus erythematosus.

There are many benefits of NP-mediated delivery of $\mathrm{CpG}$ ODNs, and the development of safe delivery systems for natural CpG ODNs in NPs is fast approaching.

\section{Acknowledgments}

This study was funded by a grant-in-aid for scientific research (C-22560777) from the Japan Society for the Promotion of Science and the Ministry of Education, Culture, Sports, Science and Technology.

\section{Disclosures}

The author reports no conflicts of interest in this work.

\section{References}

1. Tokunaga T, Yamamoto H, Shimada S, et al. Antitumor activity of deoxyribonucleic acid fraction from Mycobacterium bovis BCG: I. Isolation, physicochemical characterization, and antitumor activity. J Natl Cancer Inst. 1984;72(4):955-962.

2. Krieg AM, Yi AK, Matson S, et al. CpG motifs in bacterial DNA trigger direct B-cell activation. Nature. 1995;374(6522):546-549.

3. Hemmi H, Takeuchi O, Kawai T, et al. A Toll-like receptor recognizes bacterial DNA. Nature. 2000;408(6813):740-745.

4. Hornung V, Rothenfusser S, Britsch S, et al. Quantitative expression of Toll-like receptor 1-10 mRNA in cellular subsets of human peripheral blood mononuclear cells and sensitivity to $\mathrm{CpG}$ oligonucleatides. J Immunol. 2002;168(9):4531-4537.

5. Klinman DM, Yi AK, Beaucage SL, Conover J, Krieg AM. CpG motifs present in bacteria DNA rapidly induce lymphocytes to secrete interleukin 6, interleukin 12, and interferon gamma. Proc Natl Acad Sci U S A. 1996;93(7):2879-2883.

6. Akira S, Uematsu S, Takeuchi O. Pathogen recognition and innate immunity. Cell. 2006;124(4):783-801.

7. Jung J, Yi AK, Zhang X, Choe J, Li L, Choi YS. Distinct response of human $\mathrm{B}$ cell subpopulations in recognition of an innate immune signal, CpG DNA. J Immunol. 2002;169(5):2368-2373.

8. Bernasconi NL, Traggiai E, Lanzavecchia A. Maintenance of serological memory by polyclonal activation of human memory B cells. Science. 2002;298(5601):2199-2202.

9. Asselin-Paturel C, Brizard G, Chemin K, et al. Type I interferon dependence of plasmacytoid dendritic cell activation and migration. J Exp Med. 2005;201(7):1157-1167.

10. Ballas ZK, Rasmussen WL, Krieg AM. Induction of NK activity in murine and human cells by $\mathrm{CpG}$ motifs in oligodeoxynucleotides and bacterial DNA. J Immunol. 1996;157(5):1840-1845.

11. Napolitani G, Rinaldi A, Bertoni F, Sallusto F, Lanzavecchia A. Selected Toll-like receptor agonist combinations synergistically trigger a T helper type 1-polarizing program in dendritic cells. Nat Immunol. 2005;6(8):769-776.

12. Roman M, Martin-Orozco E, Goodman JS, et al. Immunostimulatory DNA sequences function as T helper-1-promoting adjuvants. Nat Med. 1997;3(8):849-854.

13. Hartmann G, Weiner GJ, Krieg AM. CpG DNA: a potent signal for growth activation, and maturation of human dendritic cells. Proc Natl Acad Sci U SA. 1999;96(16):9305-9319. 
14. Blackwell SE, Krieg AM. CpG-A-induced monocyte IFN-gammainducible protein-10 production is regulated by plasmacytoid dendritic cell-derived IFN-alpha. J Immunol. 2003;170(8):4061-4068.

15. Vollmer J, Jurk M, Samulowitz U, et al. CpG oligodeoxynucleotides stimulate IFN-gamma-inducible protein-10 production in human B cells. $J$ Endotoxin Res. 2004;10(6):431-438.

16. Schwarz K, Storni T, Manolova V, et al. Role of Toll-like receptors in costimulating cytotoxic T cell responses. Eur J Immunol. 2003;33(6): 1465-1470.

17. Heit A, Maurer T, Hochrein H, et al. Cutting edge: Toll-like receptor 9 expression is not required for CpG DNA-aided cross-presentation of DNA-conjugated antigens but essential for cross-priming of CD8 T cells. J Immunol. 2003;170(6):2802-2805.

18. Krieg AM. Therapeutic potential of Toll-like receptor 9 activation. Nat Rev Drug Discov. 2006;5(6):471-484.

19. Jahrsdörfer B, Weiner GJ. CpG oligodeoxynucleotides for immune stimulation in cancer immunotherapy. Curr Opin Investig Drugs. 2003; 4(6):686-690.

20. Fonseca DE, Kline JN. Use of CpG oligonucleotides in treatment of asthma and allergic disease. Adv Drug Deliv Rev. 2009;61(3):256-262.

21. Klinman DM, Klaschik S, Sato T, Tross D. CpG oligonucleotides as adjuvants for vaccines targeting infectious diseases. Adv Drug Deliv Rev. 2009;61(3):248-255.

22. Heikenwalder M, Polymenidou M, Junt T, et al. Lymphoid follicle destruction and immunosuppression after repeated $\mathrm{CpG}$ oligodeoxynucleotide administration. Nat Med. 2004;10(2):187-192.

23. Foged C, Brodin B, Frokjaer S, Sundblad A. Particle size and surface charge affect particle uptake by human dendritic cells in an in vitro model. Int J Pharm. 2005;298(2):315-322.

24. Kurreck J. Antisense technologies: improvement through novel chemical modifications. Eur J Biochem. 2003;270(8):1628-1644.

25. Agrawal S, Zhao Q. Antisense therapeutics. Curr Opin Chem Biol. 1998;2(4):519-528.

26. Malyala P, O'Hagan DT, Singh M. Enhancing the therapeutic efficacy of CpG oligonucleotides using biodegradable microparticles. Adv Drug Deliv Rev. 2009;61(3):218-225.

27. Wilson KD, de Jong SD, Tam YK. Lipid-based delivery of CpG oligonucleotides enhances immunotherapeutic efficacy. Adv Drug Deliv Rev. 2009;61(3):233-242.

28. Bianco A, Hoebeke J, Godefroy S, et al. Cationic carbon nanotubes bind to $\mathrm{CpG}$ oligodeoxynucleotides and enhance their immunostimulatory properties. J Am Chem Soc. 2005;127(1):58-59.

29. Standley SM, Mende L, Goh SL, et al. Incorporation of CpG oligonucleotide ligand into protein-loaded particle vaccines promotes antigen-specific CD8 T-cell immunity. Bioconjug Chem. 2007;18(1): 77-83.

30. Rattanakiat S, Nishikawa M, Funabashi H, Luo D, Takakura Y. The assembly of a short linear natural cytosine-phosphate-guanine DNA into dendritic structures and its effect on immunostimulatory activity. Biomaterials. 2009;30(29):5701-5706.

31. Mutwiri GK, Nichani AK, Babiuk S, Babiuk LA. Strategies for enhancing the immunostimulatory effects of $\mathrm{CpG}$ oligodeoxynucleotides. J Control Release. 2004;97(1):1-17.

32. Krug A, Rothenfusser S, Hornung V, et al. Identification of CpG oligonucleotide sequences with high induction of IFN-alpha/beta in plasmacytoid dendritic cells. Eur J Immunol. 2001;31(7):2154-2163.

33. Krieg AM. CpG motifs in bacterial DNA and their immune effects. Annu Rev Immunol. 2002;20:709-760.

34. Gürsel M, Verthelyi D, Gürsel I, Ishii KJ, Klinman DM. Differential and competitive activation of human immune cells by distinct classes of CpG oligonucleotide. J Leukoc Biol. 2002;71(5):813-820.

35. Hartmann G, Weeratna RD, Ballas ZK, et al. Delineation of a CpG phosphorothioate oligodeoxynucleotide for activating primate immune responses in vitro and in vivo. J Immunol. 2000;164(3):1617-1624.

36. Hartmann G, Krieg AM. Mechanism and function of a newly identified CpG DNA motif in human primary B cells. J Immunol. 2000;164(2):944-953.
37. Krug A, Towarowski A, Britsch S, et al. Toll-like receptor expression reveals $\mathrm{CpG}$ DNA as a unique microbial stimulus for plasmacytoid dendritic cells which synergizes with CD40 ligand to induce high amount of IL-12. Eur J Immunol. 2001;31(10):3026-3037.

38. Hartmann G, Battiany J, Poeck H, et al. Rational design of new CpG oligonucleotides that combine B cell activation with high IFN- $\alpha$ induction in plasmacytoiddendritic cells. Eur J Immunol. 2003;33(6): $1633-1641$

39. Marshall JD, Fearon K, Abbate C, et al. Identification of a novel CpG DNA class and motif that optimally stimulate B cell and plasmacytoid dendritic cell functions. J Leukoc Biol. 2003;73(6):781-792.

40. Poeck H, Wagner M, Battiany J, et al. Plasmacytoid dendritic cells, antigen, and CpG-C license human B cells for plasma cell differentiation and immunoglobulin production in the absence of T-cell help. Blood. 2004;103(8):3058-3064.

41. Vollmer J, Weeratna R, Payette P, et al. Characterization of three CpG oligodeoxynucleotide classes with distinct immunostimulatory activities. Eur J Immunol. 2004;34(1):251-262.

42. Samulowitz U, Weber M, Weeratna R, et al. A novel class of immune-stimulatory $\mathrm{CpG}$ oligodeoxynucleotides unifies high potency in type I interferon induction with preferred structural properties. Oligonucleotides. 2010;20(2):93-101.

43. Sheehan JP, Lan HC. Phosphorothioate oligonucleotides inhibit the intrinsic tenase complex. Blood. 1998;92(5):1617-1625.

44. Brown DA, Kang SH, Gryaznov SM, et al. Effect of phosphorothioate modification of oligodeoxynucleotides on specific protein binding. J Biol Chem. 1994;269(43):26801-26805.

45. Levin AA. A review of the issues in the pharmacokinetics and toxicology of phosphorothioate antisense of oligonucleotides. Biochim Biophys Acta. 1999;1489(1):69-84.

46. Henry SP, Beattie G, Yeh G, et al. Complement activation is responsible for acute toxicities in rhesus monkeys treated with a phosphorothioate oligonucleotide. Int Immunopharmacol. 2002;2(12):1657-1666.

47. Chavany C, Connell Y, Neckers L. Contribution of sequence and phosphorothioate content to inhibition of cell growth and adhesion caused by c-myc antisense oligomers. Mol Pharmarcol. 1995;48(4):738-746.

48. Crooke RM. In vitro toxicology and pharmacokinetics of antisense oligonucleotides. Anticancer Drug Des. 1991;6(6):609-646.

49. Erie D, Sinha N, Olson W, Jones R, Breslauer KA. Dumbbell-shaped, double-hairpin structure of DNA: a thermodynamic investigation. Biochemistry. 1987;26(22):7150-7159.

50. Chu BC, Orgel LE. The stability of different forms of double-stranded decoy DNA in serum and nuclear extracts. Nucleic Acids Res. 1992; 20(21):5857-5858.

51. Clusel C, Ugarte E, Enjolras N, Vasseur M, Blumenfeld M. Ex vivo regulation of specific gene expression by nanomolar concentration of double-stranded dumbbell oligonucleotides. Nucleic Acids Res. 1993; 21(15):3405-3411.

52. Schmidt M, Anton K, Nordhaus C, Junghans C, Wittig B, Worm M. Cytokine and Ig-production by CG-containing sequences with phosphorodiester backbone and dumbbell-shape. Allergy. 2006;61(1):56-63.

53. Nishikawa M, Matono M, Rattanakiat S, Matsuoka N, Takakura Y. Enhanced immunostimulatory activity of oligodeoxynucleotides by Y-shape formation. Immunology. 2008;124(2):247-255.

54. Nishikawa M, Mizuno Y, Mohri K, et al. Biodegradable CpG DNA hydrogels for sustained delivery of doxorubicin and immunostimulatory signals in tumor-bearing mice. Biomaterials. 2011;32(2);488-494.

55. Li J, Pei H, Zhu B, et al. Self-assembled multivalent DNA nanostructures for noninvasive intracellular delivery of immunostimulatory $\mathrm{CpG}$ oligonucleotides. ACS Nano. 2011;5(11):8783-8789.

56. Meng W, Yamazaki T, Nishida Y, Hanagata N. Nuclease-resistant immunostimulatory phosphodiester $\mathrm{CpG}$ oligodeoxynucleotides as human Toll-like receptor 9 agonists. BMC Biotechnol. 2011;11:88-96.

57. Kerkmann M, Costa LT, Richter C, et al. Spontaneous formation of nucleic acid-based nanoparticles is responsible for high interferon-alpha induction by $\mathrm{CpG}-\mathrm{A}$ in plasmacytoid dendritic cells. J Biol Chem. 2005; 280(9):8086-8093. 
58. Klein DC, Latz E, Espevik T, Stokke BT. Higher order structure of short immunostimulatory oligonucleotides studied by atomic force microscopy. Ultramicroscopy. 2010;110(6):689-693.

59. Lee SW, Song MK, Baek KH, et al. Effects of a hexameric deoxyriboguanosine run conjugation into $\mathrm{CpG}$ oligodeoxynucleotides on their immunostimulatory potentials. $J$ Immunol. 2000;165(7): 3631-3639.

60. Dalpke AH, Zimmermann S, Albrecht I, Heeg K. Phosphodiester CpG oligonucleotides as adjuvants: polyguanosine runs enhance cellular uptake and improve immunostimulative activity of phosphodiester $\mathrm{CpG}$ oligonucleotides in vitro and in vivo. Immunology. 2002;106(1): $102-112$.

61. Honda K, Ohba Y, Yanai H, et al. Spatiotemporal regulation of MyD88IRF-7 signaling for robust type-I interferon induction. Nature. 2005; 434(7036):1035-1040.

62. Marshall JD, Hessel EM, Gregorio J, et al. Novel chimeric immunomodulatory compounds containing short $\mathrm{CpG}$ oligodeoxynucleotides have differential activities in human cells. Nucleic Acids Res. 2003;31(17): $5122-5133$.

63. Fearon K, Marshall JD, Abbate C, et al. A minimal human immunostimulatory $\mathrm{CpG}$ motif that potently induces IFN-gamma and IFN-alpha production. Eur J Immunol. 2003;33(8):2114-2122.

64. Aoyama Y, Kanamori T, Nakai T, et al. Artificial viruses and their application to gene delivery: size-controlled gene coating with glycocluster nanoparticles. J Am Chem Soc. 2003;125(12):3455-3457.

65. Nakai T, Kanamori T, Sando S, Aoyama Y. Remarkably size-regulated cell invasion by artificial viruses: saccharide-dependent self-aggregation of glycoviruses and its consequences in glycoviral gene delivery. $J \mathrm{Am}$ Chem Soc. 2003;125(28):8465-8467.

66. Osaki F, Kanamori T, Sando S, Sera T, Aoyama Y. A quantum dot conjugated sugar ball and its cellular uptake: on the size effects of endocytosis in the subviral region. J Am Chem Soc. 2004;126(21): $6520-6521$.

67. Gao H, Shi W, Freund LB. Mechanics of receptor-mediated endocytosis. Proc Natl Acad Sci U S A. 2005;102(27):9469-9474.

68. Roberts TL, Dunn JA, Terry TD, et al. Differences in macrophage activation by bacterial DNA and CpG-containing oligonucleotides. J Immunol. 2005;175(6):3569-3576.

69. Takeshita F, Leifer CA, Gursel I, et al. Cutting edge: role of Toll-like receptor 9 in CpG DNA-induced activation of human cells. J Immunol. 2001;167(7):3555-3558.

70. Semple SC, Klimuk SK, Harasym TO, Hope MJ. Lipid-based formulations of antisense oligonucleotides for systemic delivery applications. Methods Enzymol. 2000;313:322-341.

71. Zhu Y, Meng W, Li X, Gao H, Hanagata N. Design of mesoporous silica/cytosine-phosphodiester-guanin oligodeoxynucleotide complexes to enhance delivery efficiency. J Phys Chem C. 2011;115(2): $447-452$.

72. Demento SL, Bonafé N, Cui W, et al. TLR9-targeted biodegradable nanoparticles as immunization vectors protect against West Nile encephalitis. J Immunol. 2010;185(5):2989-2997.

73. Pan X, Chen L, Liu S, Yang X, Gao JX, Lee RJ. Antitumor activity of G3139 lipid nanoparticles (LNPs). Mol Pharm. 2009;6(1):211-220.

74. Semple SC, Klimuk SK, Harasym TO, et al. Efficient encapsulation of antisense oligonucleotides in lipid vesicles using ionizeable aminolipids: formation of novel small multilamellar vesicle structures. Biochim Biophys Acta. 2001;1510(1-2):152-166.

75. Yu RZ, Geary RS, Leeds JM, et al. Pharmacokinetics and tissue disposition in monkeys of an antisense oligonucleotide inhibitor of Ha-ras encapsulated in stealth liposomes. Pharm Res. 1999;16(8): 1309-1315.

76. Zhi C, Meng W, Yamazaki T, et al. BN nanospheres as CpG ODN carriers for activation of Toll-like receptor 9. J Mater Chem. 2011; 21(14):5219-5222.

77. Bourquin C, Anz D, Zwiorek K, et al. Targeting CpG oligonucleotides to the lymph node by nanoparticles elicits efficient antitumoral immunity. J Immunol. 2008;181(5):2990-2998.
78. Klier J, May A, Fuchs S, et al. Immunostimulation of bronchoalveolar lavage cells from recurrent airway obstruction-affected horses by different $\mathrm{CpG}$-classes bound to gelatin nanoparticles. Vet Immunol Immunopathol. 2011;144(1-2):79-87.

79. Chen HC, Sun B, Tran KK, Shen H. Effects of particle size on Tolllike receptor 9-mediated cytokine profiles. Biomaterials. 2011;32(6): 1731-1737.

80. Sokolova V, Knuschke T, Kovtun A, Buer J, Epple M, Westendorf AM. The use of calcium phosphate nanoparticles encapsulating Toll-like receptor ligands and the antigen hemagglutinin to induce dendritic cell maturation and T cell activation. Biomaterials. 2010;31(21): 5627-5633.

81. Zhu Y, Meng W, Gao H, Hanagata N. Hollow mesoporous silica/poly(Llysine) particles for codelivery of drug and gene with enzyme-triggered release property. J Phys Chem C. 2011;115(28):13630-13636.

82. Ballard BE. Biopharmaceutical considerations in subcutaneous and intramuscular drug administration. J Pharm Sci. 1968;57(3):357-378.

83. Hirano K, Hunt CA. Lymphatic transport of liposome-encapsulated agents: effects of liposome size following intraperitoneal administration. J Pharm Sci. 1985;74(9):915-921.

84. Kuramoto Y, Nishikawa M, Hyoudou K, Yamashita F, Hashida M. Inhibition of peritoneal dissemination of tumor cells by single dosing of phosphodiester $\mathrm{CpG}$ oligonucleotide/cationic liposome complex. J Control Release. 2006;115(2):226-233.

85. Kuramoto Y, Kawakami S, Zhou S, Fukuda K, Yamashita F, Hashida M. Use of mannosylated cationic liposomes/immunostimulatory CpG DNA complex for effective inhibition of peritoneal dissemination in mice. J Gene Med. 2008;10(4):392-399.

86. Chen X, Wu P, Rousseas M, et al. Boron nitride nanotubes are noncytotoxic and can be functionalized for interaction with proteins and cells. J Am Chem Soc. 2009;131(3):890-891.

87. Tighe H, Takabayashi K, Schwartz D, et al. Conjugation of protein to immunostimulatory DNA results in a rapid, long-lasting and potent induction of cell-mediated and humoral immunity. Eur J Immunol. 2000;30(7):1939-1947.

88. Gürsel M, Tunca S, Ozkan M, Ozcengiz G, Alaeddinoglu G. Immunoadjuvant action of plasmid DNA in liposomes. Vaccine. 1999;17(11-12):1376-1383.

89. Gürsel I, Gürsel M, Ishii KJ, Klinman DM. Sterically stabilized cationic liposomes improve the uptake and immunostimulatory activity of $\mathrm{CpG}$ oligonucleotides. J Immunol. 2001;167(6):3324-3328.

90. Kaiser-Schulz G, Heit A, Quintanilla-Martinez L, et al. Polyactidecoglycolide microspheres co-encapsulating recombinant tandem prion protein with $\mathrm{CpG}$-oligonucleotide break self-tolerance to prion protein in wild-type mice and induce CD4 and CD8 T cell responses. J Immunol. 2007;179(5):2797-2807.

91. Nierkens S, den Brok MH, Sutmuller RP, et al. In vivo colocalization of antigen and $\mathrm{CpG}$ [corrected] within dendritic cells is associated the efficacy of cancer immunotherapy. Cancer Res. 2008;68(13): $5390-5396$.

92. Lee YR, Lee YH, Im SA, et al. Biodegradable nanoparticles containing TLR3 or TLR9 agonists together with antigen enhance MHC-restricted presentation of the antigen. Arch Pharm Res. 2010;33(11):1859-1866.

93. Erikçi E, Gürsel M, Gürsel I. Differential immune activation following encapsulation of immunostimulatory $\mathrm{CpG}$ oligodeoxynucleotide in nanoliposomes. Biomaterials. 2011;32(6):1715-1723.

94. Slütter B, Jiskoot W. Dual role of $\mathrm{CpG}$ as immune modulator and physical crosslinker in ovalbumin loaded $\mathrm{N}$-trimethyl chitosan (TMC) nanoparticles for nasal vaccination. J Control Release. 2010;148(1): 117-121.

95. Bal SM, Slütter B, Verheul R, Bouwstra JA, Jiskoot W. Adjuvanted, antigen loaded $\mathrm{N}$-trimethyl chitosan nanoparticles for nasal and intradermal vaccination: adjuvant- and site-dependent immunogenicity in mice. Eur J Pharm Sci. 2012;45(4):475-481.

96. Singh M, Ott G, Kazzaz J, et al. Cationic microparticles are an effective delivery system for immune stimulatory CpG DNA. Pharm Res. 2001; 18(10):1476-1479. 
97. Diwan M, Tafaghodi M, Samuel J. Enhancement of immune responses by co-delivery of a $\mathrm{CpG}$ oligodeoxynucleotide and tetanus toxoid in biodegradable nanospheres. J Control Release. 2002;85(1-3): 247-262.

98. Zhang XQ, Dahle CE, Baman NK, Rich N, Weiner GJ, Salem AK Potent antigen-specific immune responses stimulated by codelivery of CpG ODN and antigens in degradable microparticles. J Immunother. 2007;30(5):469-478.

99. Borges O, Cordeiro-da-Silva A, Tavares $\mathrm{J}$, et al. Immune response by nasal delivery of hepatitis B surface antigen and codelivery of a CpG ODN in alginate coated chitosan nanoparticles. Eur J Pharm Biopharm. 2008;69(2):405-416.

100. Xie H, Gursel I, Ivins BE, et al. CpG oligodeoxynucleotides adsorbed onto polylactide-co-glycolide microparticles improve the immunogenicity and protective activity of the licensed anthrax vaccine. Infect Immun. 2005;73(2):828-833.

101. Heit A, Schmitz F, Haas T, Busch DH, Wagner H. Antigen coencapsulated with adjuvants efficiently drive protective $\mathrm{T}$ cell immunity. Eur J Immunol. 2007;37(8):2063-2074.

102. Kwong B, Liu H, Irvine DJ. Induction of potent anti-tumor responses while eliminating systemic side effects via liposome-anchored combinatorial immunotherapy. Biomaterials 2011;32(22):5134-5147.

103. Stone GW, Barzee S, Snarsky V, et al. Nanoparticle-delivered multimeric soluble CD40L DNA combined with Toll-like receptor agonists as a treatment for melanoma. PLoS One. 2009;4(10):e7334.

104. Wells JW, Cowled CJ, Farzaneh F, Noble A. Combined triggering of dendritic cell receptors results in synergistic activation and potent cytotoxic immunity. J Immunol. 2008;181(5):3422-3431.

105. Harada A, Kawamura M, Matsuo T, Takahashi T, Kono K. Synthesis and characterization of a head-tail type polycation block copolymer as a nonviral gene vector. Bioconjug Chem. 2006;17(1):3-5.

106. Wagner E, Kloeckner J. Gene delivery using polymer therapeutics. Adv Polym Sci. 2006;192:135-173.
107. Nguyen DN, Green JJ, Chan JM, Langer R, Anderson DG. Polymeric materials for gene delivery and DNA vaccination. Adv Mater. 2009;21(8):847-867.

108. Meyer O, Kirpotin D, Hong K, et al. Cationic liposomes coated with polyethylene glycol as carriers for oligonucleotides. J Biol Chem. 1998;273(25):15621-15627.

109. Mahato RI, Anwer K, Tagliaferri F, et al. Biodistribution and gene expression of lipid/plasmid complexes after systemic administration. Hum Gene Ther. 1998;9(14):2083-2099.

110. Kim H, Akagi T, Akashi M. Preparation of CpG ODN-encapsulated anionic poly(amino acid) nanoparticles for gene delivery. Chem Lett. 2010;39(3):278-279.

111. Pack DW, Hoffman AS, Pun S, Stayton PS. Design and development of polymers for gene delivery. Nat Rev Drug Discov. 2005;4(7): 581-593.

112. Trubetskoy VS, Wong SC, Subbotin V, et al. Recharging cationic DNA complexes with highly charged polyanions for in vitro and in vivo gene delivery. Gene Ther. 2003;10(3):261-271.

113. Kurosaki T, Kitahara T, Fumoto S, et al. Ternary complexes of pDNA, polyethylenimine, and gamma-polyglutamic acid for gene delivery systems. Biomaterials. 2009;30(14):2846-2853.

114. Kim H, Akagi T, Akashi M. Preparation of size tunable amphiphilic poly(amino acid) nanoparticles. Macromol Biosci. 2009;9(9): $842-848$

115. Yanai H, Ban T, Wang Z, et al. HMGB proteins function as universal sentinels for nucleic-acid-mediated innate immune responses. Nature. 2009;462(7269):99-103.

116. Yanai H, Chiba S, Ban T, et al. Suppression of immune responses by nonimmunogenic oligodeoxynucleotides with high affinity for highmobility group box proteins (HMGBs). Proc Natl Acad Sci U S A. 2011;108(28):11542-11547.
International Journal of Nanomedicine

\section{Publish your work in this journal}

The International Journal of Nanomedicine is an international, peerreviewed journal focusing on the application of nanotechnology in diagnostics, therapeutics, and drug delivery systems throughout the biomedical field. This journal is indexed on PubMed Central,

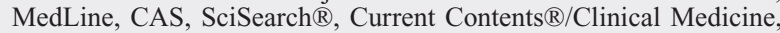

\section{Dovepress}

Journal Citation Reports/Science Edition, EMBase, Scopus and the Elsevier Bibliographic databases. The manuscript management system is completely online and includes a very quick and fair peer-review system, which is all easy to use. Visit http://www.dovepress.com/ testimonials.php to read real quotes from published authors. 